\title{
Action of the Noradrenergic System on Adult-Born Cells Is Required for Olfactory Learning in Mice
}

\author{
Melissa M. Moreno, ${ }^{1}$ Kevin Bath, ${ }^{2,3 \star}$ Nicola Kuczewski, ${ }^{1 \star}$ Joëlle Sacquet, ${ }^{1}$ Anne Didier, ${ }^{1}$ and Nathalie Mandairon ${ }^{1}$ \\ ${ }^{1}$ INSERM U1028, CNRS, UMR5292, Lyon Neuroscience Research Center, University Lyon 1, F-69000, France, ${ }^{2}$ Department of Psychiatry, Weill Cornell \\ Medical College, New York, New York 10021, and ${ }^{3}$ Department of Neuroscience, Brown University, Providence, Rhode Island 02912
}

We have previously shown that an experience-driven improvement in olfactory discrimination (perceptual learning) requires the addition of newborn neurons in the olfactory bulb (OB). Despite this advance, the mechanisms which govern the selective survival of newborn $\mathrm{OB}$ neurons following learning remain largely unknown. We propose that activity of the noradrenergic system is a critical mediator providing a top-down signal to control the selective survival of newly born cells and support perceptual learning.

In adult mice, we used pharmacological means to manipulate the noradrenergic system and neurogenesis and to assess their individual and additive effects on behavioral performance on a perceptual learning task. We then looked at the effects of these manipulations on regional survival of adult-born cells in the $\mathrm{OB}$. Finally, using confocal imaging and electrophysiology, we investigated potential mechanisms by which noradrenaline could directly influence the survival of adult-born cells.

Consistent with our hypotheses, direct manipulation of noradrenergic transmission significantly effect on adult-born cell survival and perceptual learning. Specifically, learning required both the presence of adult-born cell and noradrenaline. Finally, we provide a mechanistic link between these effects by showing that adult-born neurons receive noradrenergic projections and are responsive to noradrenaline.

Based upon these data we argue that noradrenergic transmission is a key mechanism selecting adult-born neurons during learning and demonstrate that top-down neuromodulation acts on adult-born neuron survival to modulate learning performance.

\section{Introduction}

Previous experience can lead to significant improvements in discrimination abilities which is called perceptual learning (Gilbert et al., 2001). This learning reflects an ongoing process by which animals may learn to discriminate common and potentially relevant stimuli within their immediate environment.

In previous work, we have shown that perceptual learning increased the responsiveness of the bulbar inhibitory granule cells to odorants as measured by expression of an immediate early gene (Mandairon et al., 2008b). A computational model (Mandairon et al., 2006c) as well as recent data using GAD65/67 expression and paired-pulse inhibition (Moreno et al., 2009) led us to conclude that perceptual learning produces widespread changes in inhibitory processing which can underlie the observed improvement of odor discrimination. In line with these findings, we have recently shown that inhibitory interneurons, which regulate the activity of mitral cells and are continuously generated in adulthood (Lois and Alvarez-Buylla, 1994; Petreanu and AlvarezBuylla, 2002), are required for perceptual learning to occur in the

\footnotetext{
Received Dec. 20, 2011; accepted Jan. 23, 2012.

Author contributions: M.M.M. and N.M. designed research; M.M.M., N.K., J.S., and N.M. performed research; M.M.M., K.B., N.K., A.D., and N.M. analyzed data; M.M., K.B., A.D., and N.M. wrote the paper.

This work was supported by the CNRS and Région Rhône-Alpes. We thank Dr. Marc Marien (Centre de Recherche Pierre Fabre) for the gift of the dexefaroxan.

*K.B. and N.K. contributed equally.

Correspondence should be addressed to Nathalie Mandairon, INSERM U1028, CNRS UMR 5292, Lyon Neuroscience Research Center, 50 Avenue Tony Garnier, F-69007 Lyon, France. E-mail: nathalie.mandairon@olfac.univ-lyon1.fr. DOI:10.1523/JNEUROSCI.6335-11.2012

Copyright $\odot 2012$ the authors $\quad 0270-6474 / 12 / 323748-11 \$ 15.00 / 0$
}

olfactory system (Moreno et al., 2009). This suggests that perceptual plasticity relies on long-term changes in odor processing at the level of the olfactory bulb (OB) involving increased survival of adult-born neurons.

However, the mechanisms governing the integration and survival of adult-born neurons during learning are unknown. A potential candidate is noradrenaline (NA). Indeed, the granule cell layer of the $\mathrm{OB}$, the main target of neurogenesis is largely innervated by the noradrenergic system coming from the locus ceruleus (Shipley et al., 1985; McLean et al., 1989). NA plays a critical role in olfactory perception as well as learning (Fletcher and Chen, 2010). For example, in newborn rats, NA is involved in the acquisition of conditioned odor preferences (Sullivan and Wilson, 1994; Moriceau and Sullivan, 2004) and in the learning of an odor-based attachment to the mother (Sullivan et al., 2000). In adult animals, the presence of NA is required for the modulation in the $\mathrm{OB}$ of electrophysiological responses associated with olfactory learning (Gray et al., 1986), for longlasting suppression of odor responses after pairing locus ceruleus stimulation with odor presentation (Shea et al., 2008), for spontaneous discriminations (Mandairon et al., 2008a) and short-term olfactory memory (Veyrac et al., 2007, 2009). Interestingly, olfactory enrichment stimulates the noradrenergic system (Veyrac et al., 2009; Rey et al., 2012) and NA is a positive modulator of newborn neuron survival (Bauer et al., 2003; Bovetti et al., 2011).

In the present study, we were interested in the potential role of NA as a mediating signal for adult-born neuron integration during perceptual learning. We found that the improvement of odor 
Table 1. Odor pairs used for olfactory discrimination testing (cross-habituation testing) and corresponding $\mathrm{v} / \mathrm{v}$ dilutions ( $1 \mathrm{~Pa})$

\begin{tabular}{ll}
\hline Odor pairs & Odors \\
\hline 1 & +Limonene and - Limonene $(0.204 \%)$ \\
2 & Pentanol $(0.074 \%)$ and Butanol $(0.021 \%)$ \\
3 & Decanal $(1.78 \%)$ and $(2)$-Dodecanone $(12.5 \%)$ \\
4 & $(+)$ Limonene $(0.204 \%)$ and Decanal $(1.78 \%)$ \\
5 & Isoamyl acetate $(0.05 \%)$ and Octanal $(0.148 \%$ \\
\hline
\end{tabular}

Each pair is composed of perceptually similar odorants ( 1 to 3 ) or dissimilar odorants ( 4 and 5 ) diluted in mineral oil to have similar vapor pressure.

discrimination due to enrichment is under the control of the noradrenergic system. Moreover, we found that the noradrenergic system acted on adult-born cells to enhance the discrimination ability of mice. These data are supported by experiments showing NA projections onto adult-born neurons and an electrical response to NA application. These data provide a significant advancement in our understanding of the role of neurogenesis in the adult brain, its regulation by internal inputs (NA) in response to environmental stimuli, and its contribution to improvements in perceptual ability.

\section{Materials and Methods}

\section{Animals}

Ninety-seven adult male C56BL/6J mice (Charles River) aged 8-weeks at the beginning of the experiments, were housed under a $12 \mathrm{~h}$ light/dark cycle in an environmentally controlled room. All behavioral training was conducted in the afternoon (2:00-5:00 P.M.). All efforts were made to minimize the number of animals used, and the experimental procedures were in accordance with the European Community Directive of 24 November 1986 (86/609/EEC), and the French Ethical Committee.

\section{Experimental design}

For all experiments, before any drug treatment and/or environmental manipulations (enrichment with $+/$-limonene), all groups of animals were tested for their ability to spontaneously discriminate between three pairs of similar odorants: + and -limonene, pentanol/butanol, and decanal/dodecanone using an olfactory cross habituation test (see below). To assess the efficacy of our manipulations to modulate olfactory discrimination abilities, mice were then subjected to an identical post-test, beginning the day after the end of treatment, again using all of the three odorant pairs to assess changes in their discrimination ability.

\section{Olfactory cross-habituation test}

We used a cross-habituation test (Cleland et al., 2002; Mandairon et al., 2006c; Imayoshi et al., 2008; Breton-Provencher et al., 2009; Lazarini et al., 2009; Moreno et al., 2009) to assess spontaneous discrimination because it is a naturalistic task which relies upon intrinsic motivation whereas go-no go or other associative tasks rely upon exogenous rewards which can influence learning and engage other systems.

Behavioral testing. Briefly, the olfactory cross-habituation task assesses the degree to which mice are able to spontaneously discriminate between odorants by habituating them to an odorant (Ohab) and measuring their cross-habituation to a second odorant (Otest). If the second odorant is not discriminated from the first, it will not elicit an increased investigation response by the mouse. Each presentation lasts $50 \mathrm{~s}$ and is separated by $5 \mathrm{~min}$. Odors are presented using a tea ball hanging on the cover of the cage and containing $60 \mu \mathrm{l}$ of the diluted odor (1 Pa, Table 1) on filter paper (Whatman No. 1). Odors are renewed between each test. Each odorant of each pair was used alternatively as habituation or test odorant. Animal groups were encoded for the test so that the experimenter was unaware of the identity of the animal group. The amount of time that the mice investigated the odorant was recorded during all trials. Only mice that investigated Ohab for at least $1 \mathrm{~s}$ during its first presentation were included in the analysis. Outlier trials that deviated from the mean by more than two SDs were also excluded from analysis (between 2 and 5 outlier trials among 100 trials total per experimental group for one odor
Table 2. Treatments used for the different experimental groups

\begin{tabular}{llll}
\hline Experiment & Enrichment odors & Drugs used during the enrichment & $\begin{array}{l}\text { Size of } \\
\text { group }\end{array}$ \\
\hline 1 & No odor & Saline & 10 \\
1 & $+/-$ Limonene & Saline & 10 \\
1 & No odor & Labetalol $(25 \mathrm{mg} / \mathrm{kg}$, i.p. $)$ & 10 \\
1 & $+/-$ Limonene & Labetalol $(25 \mathrm{mg} / \mathrm{kg}$, i.p. $)$ & 10 \\
1 & No odor & Dexefaroxan $(0.63 \mathrm{mg} / \mathrm{kg}, \mathrm{i} . \mathrm{p})$. & 10 \\
2 & No odor & Dexefaroxan $(0.63 \mathrm{mg} / \mathrm{kg}, \mathrm{i.p.})+$ saline & 15 \\
& & intracerebral infusion & \\
2 & No odor & Dexefaroxan $(0.63 \mathrm{mg} / \mathrm{kg}, \mathrm{i} . \mathrm{p})+$. AraC & 15 \\
& & intracerebral infusion & \\
\hline
\end{tabular}

Experiment 1: Animals were submitted to a $10 \mathrm{~d}+/$-limonene enrichment period or were not enriched. In parallel, to modulate the noradrenergic system, animals were injected with saline solution, dexefaroxan or labetalol. Experiment 2: Animals infused with AraC or Saline solution in the subventricular zone were treated during a $10 \mathrm{~d}$ period with dexefaroxan in the absence of odorant.

pair were excluded). The pairs of similar odorants used for the crosshabituation test were the following: $+/$-limonene, pentanol/butanol and decanal/dodecanone (Table 1). Odorant pairs were chosen based upon their perceptual similarity and their activation of overlapping regions of the glomerular cell layer. Indeed, butanol and pentanol are partially overlapping with limonene whereas decanal and dodecanone are more distinct from limonene (Mandairon et al., 2006c). All odor pairs were encoded so that the experimenter was unaware of the identity of each odor.

Statistical analyses. All data were analyzed using Systat statistical software (Systat Software). The data for each odor pair were analyzed by ANOVA followed by post hoc Fisher test to determine (1) if the time of investigation during Ohab4 is significantly lower than during Ohab1 (habituation) and (2) if the time of investigation Otest is significantly higher than the one of Ohab4 (discrimination). The level of significance was set to 0.05 .

Drug treatment and/or environmental manipulations

In Experiment 1, mice were randomly assigned to five experimental groups (Table 2).

Odor enrichment and control. Odor enrichment consisted of exposure with + and -limonene for $1 \mathrm{~h}$ per day for 10 consecutive days. Odors were presented simultaneously on two separate swabs containing $100 \mu \mathrm{l}$ of pure odor placed in two separate tea balls and hung from the cover of the animals cage (Mandairon et al., 2006a). Control, non-enriched mice were housed under the same conditions except that the two tea balls were left empty.

Dexefaroxan and labetalol drug treatment. Twenty minutes before each enrichment session, each mouse received a single intraperitoneal injection of $100 \mu \mathrm{l}$ of freshly prepared drug or saline solution (Table 2; a total of 10 injections). The two noradrenergic agents used were the $\alpha 2$ presynaptic receptor antagonist dexefaroxan hydrochloride $(0.63 \mathrm{mg} / \mathrm{kg}$ in saline; synthesized and provided by Centre de Recherche Pierre Fabre, Castres, France) promoting noradrenaline release and the $\alpha 1-\beta$ receptor antagonist labetalol hydrochloride $(25 \mathrm{mg} / \mathrm{kg}$ in saline; (Sigma) (Veyrac et al., 2007).

\section{Cellular analysis}

BrdU injections. Newly born cells of the OB require several days to migrate from the subventricular zone to the $\mathrm{OB}$, where they differentiate into mature granule and periglomerular cells. Thus, we injected mice with bromodeoxyuridine (BrdU; Sigma; $50 \mathrm{mg} / \mathrm{kg}$ in saline three times daily at $2 \mathrm{~h}$ intervals, i.p.) $8 \mathrm{~d}$ before enrichment to investigate the survival of BrdU-labeled cells that are in the OB during the period of enrichment. Animals were killed $25 \mathrm{~d}$ after the injections (Fig. $1 \mathrm{~A}$ ).

Histology. Five mice were randomly chosen from each experimental group and were put in a clean cage for $1 \mathrm{~h}$. To investigate immediate early gene expression in response to odorant exposure, mice were then presented with a tea ball containing $100 \mu$ l of pure + limonene or decanal for $1 \mathrm{~h}$. One hour after the end of the odor stimulation, mice were deeply anesthetized (Urethane, $2 \mathrm{~g} / \mathrm{kg}$ ) and were killed by intracardiac perfusion of $50 \mathrm{ml}$ of cold fixative (paraformaldehyde $4 \%$ in PBS, pH 7.4). Brains 


\section{A}
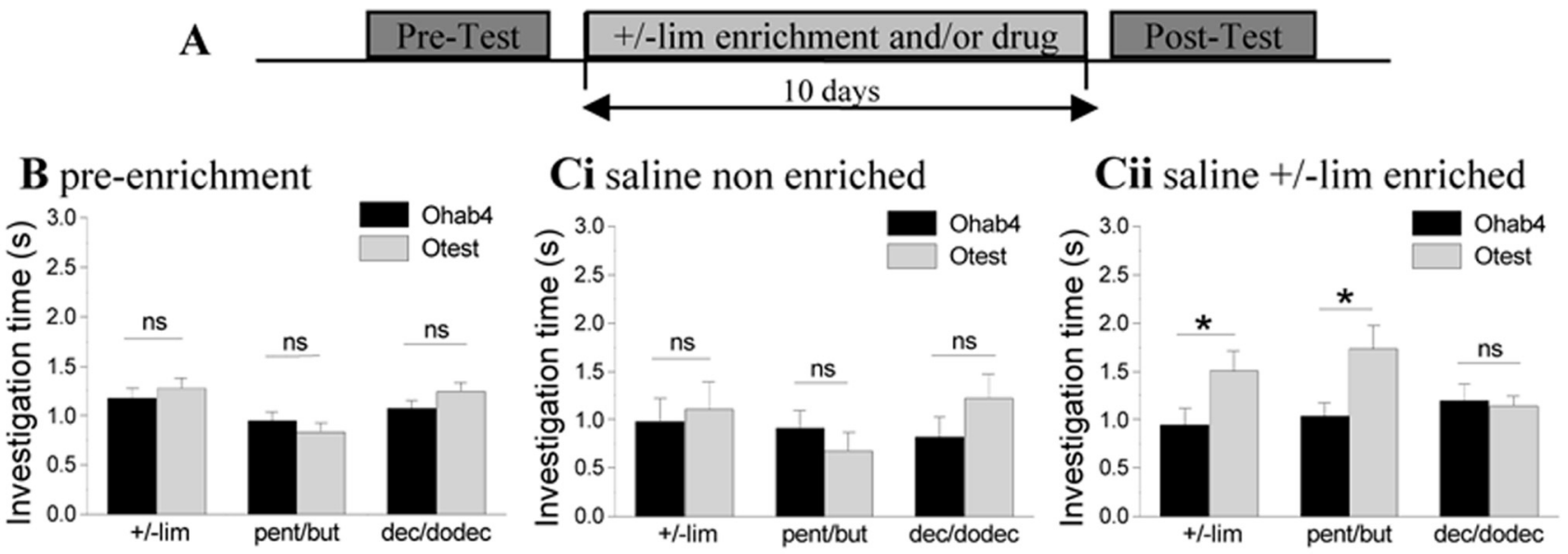

Ciii labetalol +/-lim enriched

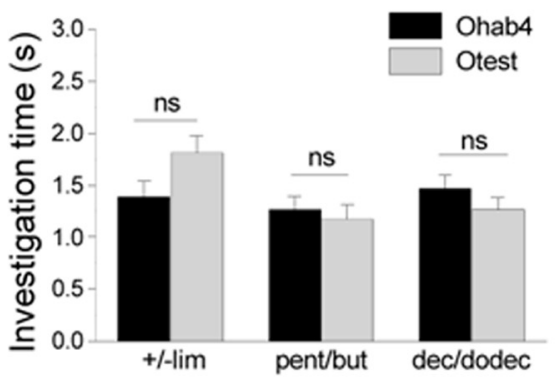

Civ labetalol non enriched

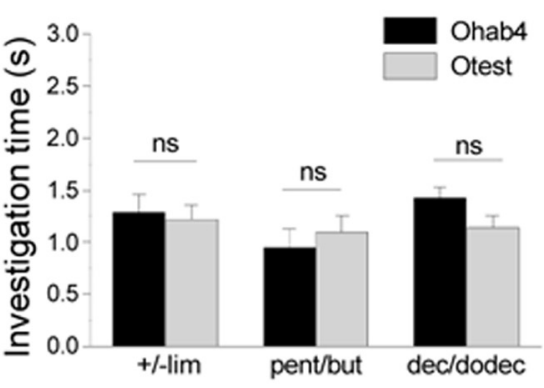

Cv dexefaroxan non enriched

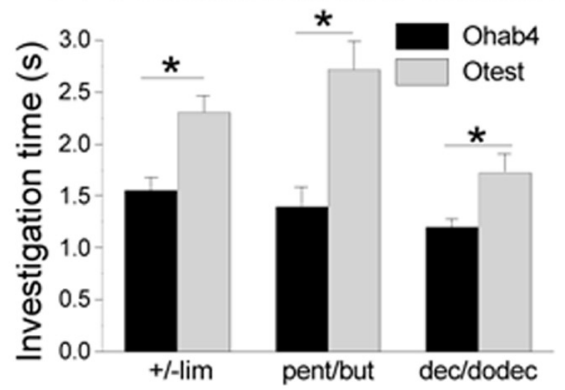

Di

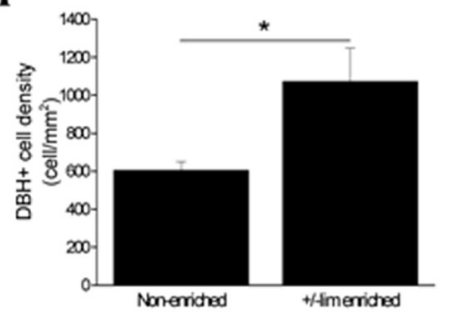

Dii

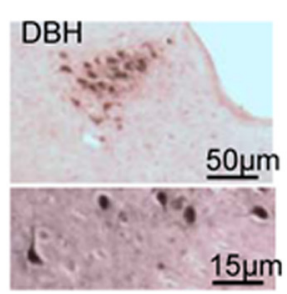

Figure 1. Perceptual learning is under control of the noradrenergic system. $\boldsymbol{A}$, Time course of the experiment. Spontaneous discrimination between $+/-$ limonene $(+/-$ lim), pentanol/ butanol (pent/but), and decanal/dodecanone (dec/dodec) was tested before and after a period of olfactory enrichment and/or drug treatment. Experimental groups were enriched by introducing $+/-$ lim into the home cage for $1 \mathrm{~h}$ periods over $10 \mathrm{~d}$ and treated during the same period of time with dexefaroxan, labetalol, or saline. $B, C$, Behavioral discrimination was tested before (B) and after (C) the treatment period. The two odorants of each pair are cross-habituated before the enrichment period and thus not discriminated $(\boldsymbol{B})$, as well as in the control non-enriched group $(\boldsymbol{C} \boldsymbol{C})$. After enrichment with $+/-\lim$, two of the three odor pairs are discriminated ( $+/-\lim$ and pent/but) (Cii). Treatment with labetalol with (Ciii) or without (Civ) enrichment prevents the improvement of discrimination. In contrast, after treatment with dexefaroxan without any enrichment, all three odor pairs are discriminated $(\mathbf{C v}) .^{*} p<0.05$ in response magnitude between trials 4 (Hab4) and 5 (Otest). Di, Quantification of DBH-positive neurons in the locus ceruleus. Odor enrichment increased the density of DBH-positive cells compared with non-enriched animals. ${ }^{*} p<0.05$. Dii, DBH labeling in the locus ceruleus. The data are expressed as mean values \pm SEM.

were removed, postfixed, frozen rapidly and then stored at $-20^{\circ} \mathrm{C}$ before sectioning with a cryostat.

BrdU immunocytochemistry. The protocol has been described in detail previously (Mandairon et al., 2003). Sections were incubated overnight in a mouse anti-BrdU antibody (1:100, Millipore Bioscience Research Reagents) at $4^{\circ} \mathrm{C}$ followed by a biotinylated anti-mouse secondary antibody (1:200, Vector Laboratories) for $2 \mathrm{~h}$. The sections were then processed through an avidin-biotin-peroxidase complex (ABC Elite Kit, Vector Laboratories). Following dehydration in graded ethanols, the sections were defatted in xylene and coverslipped in DPX (Fluka, Sigma).

Zif268 immunocytochemistry. Sections were incubated overnight in a rabbit anti-Zif268 antibody (1:1000, Santa Cruz Biotechnology) at room temperature for $16 \mathrm{~h}$. Sections were then incubated in a biotinylated anti-rabbit secondary antibody (1:200, Vector Laboratories) for $2 \mathrm{~h}$. The remaining treatments were similar to those for the BrdU labeling.

Data analysis (BrdU and Zif-268 levels). The $\mathrm{OB}$ of mice was coronally sectioned $(14 \mu \mathrm{m})$. Every fifth section was processed for immunostain- ing (sampling interval $=70 \mu \mathrm{m}$ ). Within each analyzed section, every BrdU- or Zif268-positive cell was counted in the granule layer of the right OB using mapping software (Mercator, Explora Nova, La Rochelle, France) coupled to Zeiss microscope. The mean positive cell density was calculated and averaged within each experimental group. Betweengroups comparisons were performed by ANOVA followed by a post hoc Fisher test. The level of significance was set to 0.05 .

To confirm the link between Zif268 expression and neural activity, the right $\mathrm{OB}$ of four additional mice was sensory deprived by naris occlusion using plug insertion as described in our previous report (Mandairon et al., 2006b). Zif268 expression has been assessed on 4 sections per animals in both right and left OBs. Between-OB comparison was performed by paired $t$ test.

BrdU- and Zif-268-positive cell mapping. Maps of positive cells were constructed as follows: The layer was divided into 36 sectors of $10^{\circ}$ with a reference axis drawn parallel to the most ventral aspect of the subependymal layer of the OB (Mandairon et al., 2006d). The cell density (number 
of labeled profiles $/ \mu \mathrm{m}^{2}$ ) was calculated for each sector. Measurements were then merged into arrays of $10^{\circ} \times 70 \mu \mathrm{m}$ bins. The most rostral aspect of the accessory OB served as an anatomical landmark to align the sections across animals (Matlab v.6). For visualization of the positive cell density maps, arrays were averaged across animals within each group, and colored image plot of the data was constructed in Matlab v.6.

Double-labeling immunohistochemistry. To determine the phenotype of BrdU-positive cells in the $\mathrm{OB}$, double-labeling was performed using a rat anti-BrdU (1:100, Harlan Sera-Lab) and a mouse anti-NeuN (1:500, Millipore Bioscience Research Reagents) or a rabbit anti-calbindin (1:500, Millipore Bioscience Research Reagents). For the Zif268/BrdU double labeling, a rabbit anti-Zif268 antibody (1:1000, Santa Cruz Biotechnology) was used. The appropriate secondary antibodies, coupled to Alexa Fluor 633 (Invitrogen) for revelation of BrdU and Alexa Fluor 488 (Invitrogen) for revelation of the different markers, were used.

Double-labeling analysis. On five animals of each experimental group, 20-25 BrdU-positive cells per animal were examined for colabeling with NeuN or Zif268. Double-labeling was analyzed by pseudo-confocal scanning microscopy (apotome, Zeiss). Each labeled cell was examined along the $z$-axis to ensure proper identification of double labeled cells. A percentage of double labeled cells was calculated for each group and compared using ANOVA followed by Fisher post hoc test.

AraC treatment and BrdU labeling. To determine the target of the noradrenergic system during perceptual learning, we used mitotic blocker AraC to inhibit neurogenesis (Moreno et al., 2009; Sultan et al., 2010). A new pool of 40 adult C57BL/6 mice were anesthetized with a cocktail injection of $50 \mathrm{mg} / \mathrm{kg}$ ketamine and $7.5 \mathrm{mg} / \mathrm{kg}$ xylazine (i.p.) and secured in a stereotaxic instrument (Narishige Scientific Instruments) (Table 2, Experiment 2). All animals were implanted with an osmotic pump (Alzet Osmotic pumps 2004). The cannula was located in the left subventricular zone (SVZ) (anteroposterior, +1.2 mm; lateral, +0.9 $\mathrm{mm}$, dorsoventral, $-3 \mathrm{~mm}$ ). Mice were injected with $\mathrm{AraC}(4 \%$ in $0.9 \%$ saline, Sigma) $(n=25)$ or saline solution $(n=15)$ at a flow rate of 0.25 $\mu \mathrm{l} / \mathrm{h}$ (Table 2, Experiment 2). To assess the level of neurogenesis, BrdU was injected ( $50 \mathrm{mg} / \mathrm{kg}, 3$ times every $2 \mathrm{~h}$ ) $3 \mathrm{~d}$ after the beginning of AraC infusion. All animals (AraC- or saline-infused mice) were injected with dexefaroxan once a day during $10 \mathrm{~d}$ with no odor enrichment. At the end of the treatment by dexefaroxan and before the discrimination testing, the infusion of AraC or saline was stopped by sectioning and plugging the catheter between the pump and the cannulae, under light anesthesia with $25 \mathrm{mg} / \mathrm{kg}$ ketamine and $3.25 \mathrm{mg} / \mathrm{kg}$ xylazine (i.p.). Then, a day after the end of the drug treatment and AraC/Saline infusion, discrimination performances were assessed on three similar odor pairs (+/-limonene, pentanol/butanol and decanal/dodecanone) and two dissimilar odor pairs (+limonene/decanal and isoamyl acetate/octanal) using a crosshabituation task.

Dopamine $\beta$-hydroxylase immunohistochemistry and quantification. To detect noradrenergic neurons in the locus ceruleus, immunohistochemistry of the noradrenaline synthetic enzyme dopamine $\beta$-hydroxylase (DBH) was performed on brainstem sections including the locus ceruleus of 5 animals per group (Rey et al., 2012). Brain sections were incubated in Target Retrieval Solution for $20 \mathrm{~min}$ at $98^{\circ} \mathrm{C}$. After cooling, they were incubated for $90 \mathrm{~min}$ in $5 \%$ normal serum, 5\% BSA, and $0.125 \%$ Triton $\mathrm{X}-100$ and then in rabbit anti-DBH primary antibody (1:200; Santa Cruz Biotechnology) for $40 \mathrm{~h}$ at $4^{\circ} \mathrm{C}$. Sections were then incubated in a biotinylated goat anti-rabbit secondary antibody (1:200; Vector Laboratories) for $2 \mathrm{~h}$. The remaining treatments were similar to those for the BrdU labeling. For each animal, all sections (intersection interval $140 \mu \mathrm{m}$ ) containing DBH-positive cells were analyzed. The area containing DBH-positive cells was delineated and labeled cells (very dark cells with marked key lines) were counted. The number of DBH-positive cells was related to the selected area and data were expressed as the number of positive cells per $\mathrm{mm}^{2}$ (density). Statistical analysis was performed by an unilateral $t$ test comparing non-enriched and enriched animals.

Norepinephrine transporter-newborn GFP cell double-labeling. The subventricular zone of the experimental mice $(n=3)$ was stereotaxically injected with lentiviruses expressing the GFP driven by the PGK promoter (200 nl/injection site) using a Narishige Scientific Instruments.
The coordinates were as follows: anteroposterior $+0.5 \mathrm{~mm}$, mediolateral $\pm 1.1 \mathrm{~mm}$, dorsoventral $-1.7 \mathrm{~mm}$, and anteroposterior $+1 \mathrm{~mm}$, mediolateral $\pm 1 \mathrm{~mm}$ and dorsoventral $-2.3 \mathrm{~mm}$. Mice were then killed $15 \mathrm{~d}$ after injection to observe whether NA project on newborn cells during the enrichment period. Brains were removed, postfixed, frozen rapidly and then stored at $-20^{\circ} \mathrm{C}$ before sectioning with a cryostat (coronal sections of $40 \mu \mathrm{m}$ ). Immunohistochemistry of norepinephrine transporter (NET), a marker of noradrenergic terminals was performed in the OB. OB sections were rehydrated and incubated for $30 \mathrm{~min}$ in Triton $\mathrm{X}-1000.1 \%$, followed by a $90 \mathrm{~min}$ incubation in $5 \%$ normal horse serum in $5 \%$ BSA and $0.1 \%$ Triton X-100 to block unspecific binding, and incubated for $72 \mathrm{~h}$ at $4^{\circ} \mathrm{C}$ in mouse anti-rat NET antibody (1:1000; MAb Technologies). Sections were then incubated in horse anti-mouse biotinylated antibody (1:200; Vector Laboratories) for $2 \mathrm{~h}$. They were then incubated in streptavidin-coupled Alexa Fluor 488 (1:1000; Invitrogen). Double-labeling was analyzed by pseudo-confocal microscopy (Zeiss microscope equipped with an apotome).

\section{Electrophysiological experiments}

For electrophysiological experiment, eight additional mice were injected with lentiviruses expressing the GFP as described previously. From 12 to $18 \mathrm{~d}$ after lentiviruses injections animals were anesthetized with intraperitoneal injection of $50 \mu \mathrm{l}$ of ketamine $(50 \mathrm{mg} / \mathrm{ml})$ and killed by decapitation. The head was quickly immersed in ice-cold $\left(2-4^{\circ} \mathrm{C}\right.$ ) cutting artificial CSF (Cutting-ACSF containing, in mm: 135 Choline chloride, $2.5 \mathrm{KCl}, 25 \mathrm{NaHCO}_{3}, 1.25 \mathrm{NaH}_{2} \mathrm{PO}_{4}, 1$ Na-piruvate, $0.5 \mathrm{CaCl}_{2}, 7 \mathrm{MgCl}_{2}, 7$ glucose). OBs were removed as previously described (Palouzier-Paulignan et al., 2002) and cut in horizontal slices (350 $\mu \mathrm{m}$ thick) using a Leica VT1000s vibratome. Slices were incubated in ACSF (containing, in mM: $125 \mathrm{NaCl}, 4 \mathrm{KCl}, 25 \mathrm{NaHCO}_{3}, 1.25$ $\mathrm{NaH}_{2} \mathrm{PO}_{4}, 0.3$ ascorbic acid, $1 \mathrm{Na}$-piruvate, $1.4 \mathrm{CaCl}_{2}, 1 \mathrm{MgCl}_{2}, 5.5$ glucose; $\mathrm{pH}=7.4)\left(\right.$ oxygenated with $\left.95 \% \mathrm{O}_{2} / 5 \% \mathrm{CO}_{2} ; \mathrm{pH}=7.4\right)$ at $32^{\circ} \mathrm{C}$ for $1 \mathrm{~h}$ and then at room temperature $\left(25 \pm 2^{\circ} \mathrm{C}\right)$. The osmolarity was adjusted to $330 \mathrm{mOsm}$ with sucrose. The slices were transferred into a recording chamber mounted on an upright microscope (Axioskop FS, Zeiss) and were continuously superfused with oxygenated $31 \pm 1^{\circ} \mathrm{C}$ ACSF $(4 \pm 1 \mathrm{ml} / \mathrm{min})$. Neurons were visualized using a $40 \times$ objective with differential interference contrast optics (Nomarski) or infrared illumination (Hamamatsu camera). Whole-cell recordings were performed on GFP-expressing granular neurons visualized by epifluorescence (excitation 395-440 nm, emission $470 \mathrm{~nm}$; Zeiss filter set 05) using an RK-400 amplifier (Bio-Logic). The signal was sampled at $10 \mathrm{kHz}$ and low-pass filtered at $1 \mathrm{kHz}$. Borosilicate microelectrodes (outer diameter, $1.5 \mathrm{~mm}$; inner diameter, $0.86 \mathrm{~mm}$; Harvard Apparatus) were filled with the following solution (in mM): $121 \mathrm{KMeSO}_{4}, 13.5 \mathrm{KCl}, 10 \mathrm{HEPES}$, $1 \mathrm{MgCl}_{2}, 0.5 \mathrm{CaCl}_{2}$, and 5 EGTA, $310 \mathrm{mOsm}$ adjusted with $\mathrm{KCl}, \mathrm{pH}=$ 7.3. NA was diluted in ACSF at a final concentration of $10 \mu \mathrm{M}$ and was bath applied.

\section{Results}

\section{Perceptual learning depends upon noradrenergic activity}

To assess the role of the noradrenergic system during perceptual learning, we investigated the ability of mice to discriminate between perceptually similar odorants with or without noradrenergic manipulation during enrichment.

To assess discrimination, we used a cross-habituation task consisting of 4 habituations trials followed by one test trial. Habituation curves are not presented since all groups of mice from all experiments habituated correctly (Table 3 ). The discrimination performances are presented Figure 1 (Hab4 compared with Otest).

An overall ANOVA with experimental groups (saline nonenriched, saline enriched, dexefaroxan, labetalol non-enriched and labetalol enriched), test (pre-enrichment test and postenrichment test), and trial number as main effects showed significant effect of experimental group $\left(F_{(4,894)}=12.694 p<0.0001\right)$, of test $\left(F_{(1,894)}=9.097 p<0.003\right)$ or of trial number $\left(F_{(4,894)}=\right.$ 
Table 3. Habituation and discrimination performances after enrichment and/or drug injections

\begin{tabular}{|c|c|c|c|c|c|}
\hline \multirow[b]{2}{*}{ Groups } & \multirow[b]{2}{*}{ Odor pairs } & \multicolumn{2}{|l|}{ ANOVA } & \multicolumn{2}{|c|}{ Post hoc Fisher test } \\
\hline & & Fvalue & $p$ value & Habituation & Discrimination \\
\hline ne non-en & $\begin{array}{l}+1-\lim \\
\text { Pent/but } \\
\text { Dec/dodec }\end{array}$ & $\begin{array}{l}F_{(4,38)}=2.668 \\
F_{(4,55)}=6.621 \\
F_{(4,47)}=3.252\end{array}$ & $\begin{array}{l}p=0.047 \\
p<0.0001 \\
p=0.020\end{array}$ & $\begin{array}{l}p=0.008 \\
p=0.001 \\
p=0.006\end{array}$ & $\begin{array}{l}p=0.754, \mathrm{no} \\
p=0.328, \mathrm{no} \\
p=0.156, \mathrm{no}\end{array}$ \\
\hline $\begin{array}{l}\text { Saline }+/-\lim \\
\text { enriched }\end{array}$ & $\begin{array}{l}+/-\lim \\
\text { Pent/but } \\
\text { Dec/dodec }\end{array}$ & $\begin{array}{l}F_{(4,66)}=4.680 \\
F_{(4,49)}=3.209 \\
F_{(4,58)}=6.292\end{array}$ & $\begin{array}{l}p=0.002 \\
p=0.021 \\
p<0.0001\end{array}$ & $\begin{array}{l}p<0.0001 \\
p=0.006 \\
p=0.001\end{array}$ & $\begin{array}{l}p=0.029, \text { yes } \\
p=0.038, \text { yes } \\
p=0.782, \text { no }\end{array}$ \\
\hline $\begin{array}{l}\text { Labetalol non- } \\
\text { enriched }\end{array}$ & $\begin{array}{l}+/-\lim \\
\text { Pent/but } \\
\text { Dec/dodec }\end{array}$ & $\begin{array}{l}F_{(4,70)}=4.024 \\
F_{(4,49)}=8.745 \\
F_{(4,66)}=6.499\end{array}$ & $\begin{array}{l}p=0.005 \\
p<0.0001 \\
p<0.0001\end{array}$ & $\begin{array}{l}p=0.002 \\
p<0.0001 \\
p=0.004\end{array}$ & $\begin{array}{l}p=0.787, \mathrm{no} \\
p=0.648, \mathrm{no} \\
p=0.096, \mathrm{no}\end{array}$ \\
\hline $\begin{array}{l}\text { Labetalol }+/-\lim \\
\text { enriched }\end{array}$ & $\begin{array}{l}+/-\lim \\
\text { Pent/but } \\
\text { Dec/dodec }\end{array}$ & $\begin{array}{l}F_{(4,70)}=6.189 \\
F_{(4,63)}=2.530 \\
F_{(4,64)}=6.877\end{array}$ & $\begin{array}{l}p<0.0001 \\
p=0.049 \\
p<0.0001\end{array}$ & $\begin{array}{l}p<0.0001 \\
p=0.028 \\
p=0.001\end{array}$ & $\begin{array}{l}p=0.072, \mathrm{no} \\
p=0.650, \mathrm{no} \\
p=0.393, \mathrm{no}\end{array}$ \\
\hline Dexefaroxan & $\begin{array}{l}+/-\lim \\
\text { Pent/but } \\
\text { Dec/dodec }\end{array}$ & $\begin{array}{l}F_{(4,72)}=7.793 \\
F_{(4,63)}=9.116 \\
F_{(4,71)}=4.657\end{array}$ & $\begin{array}{l}p<0.0001 \\
p<0.0001 \\
p=0.002\end{array}$ & $\begin{array}{l}p<0.0001 \\
p<0.0001 \\
p<0.0001\end{array}$ & $\begin{array}{l}p=0.003, \text { yes } \\
p<0.0001 \text {, yes } \\
p=0.026 \text {, yes }\end{array}$ \\
\hline
\end{tabular}

Pent, Pentanol; but, butanol; Dec, decanal; dodec, (2)-dodecanone; lim, limonene; iso, isoamyl acetate; oct, octanal.

$44.253 p<0.0001)$. An interaction between experimental group and test was observed $\left(F_{(4,894)}=5.444 p<0.0001\right)$, indicating that the observed effect of test depends on the experimental groups.

As previously described, all mice failed to spontaneously discriminate between all three odor pairs during pre testing (Fig. $1 B$; see Table 3 for statistics details). Ten days later, mice that did not receive enrichment continued to fail to spontaneously discriminate odorant pairs (Fig. 1 Ci; Table 3 ). Mice receiving $+/-$ limonene enrichment showed a significant enhancement in discrimination abilities for $+/$-limonene and butanol/pentanol (which are partially similar to the limonene) but not for decanal/ dodecanone (which are very different from the limonene; Fig. 1Cii; Table 3; Mandairon et al., 2006c).

Mice treated during enrichment with labetalol failed to show improvements in discrimination ability (Fig. 1Ciii; Table 3) suggesting that perceptual learning depends upon NA.

As a control, an additional group of mice was injected with labetalol without any enrichment. These animals did not discriminate any of the three odor pairs (Fig. 1Civ; Table 3). This failure to improve their ability to discriminate between odorants was not likely due to impairments in olfactory sensitivity, novelty detection, or changes in arousal, as labetalol-treated mice did not differ from other groups in the initial level of odorant investigation $\left(F_{(4,66)}=2.104, p>0.05\right)$, or basal body weight (an indicator of general health, data not shown).

These initial findings strongly suggest that NA is a mediator of enrichment-induced enhancements in discrimination. To confirm this, we used a similar paradigm, but treated non-enriched animals with dexefaroxan a drug that increases NA neurotransmission (Veyrac et al., 2007), to investigate whether NA stimulation mimics olfactory enrichment. Mice treated with dexefaroxan showed a significant increase in their ability to discriminate between odorant pairs, succeeding in discriminating all 3 odorant pairs (Fig. 1Cv; Table 3).

Together, these data suggest that perceptual learning is not only dependent upon increased NA activity, but increased NA activity is sufficient to drive improvements in olfactory discrimination abilities.

To further document the involvement of NA in perceptual learning, we looked at the activation of the noradrenergic system following enrichment. For that purpose, we evaluated the density of DBH-positive cells in the locus ceruleus of non-enriched and enriched animals. We found that the density of DBH-positive cells was increased in the enriched animals compared with the control non-enriched animals $(p=0.015$; Fig. $1 D)$. These results showed that learning raised noradrenergic system activity.

\section{Neurogenesis is spatially enhanced during perceptual learning and regulated by noradrenergic system}

We were next interested in understanding the neural substrates of improved performance, both following olfactory perceptual learning as well as following pharmacological stimulation of NA activity. Impairments in adult $\mathrm{OB}$ neurogenesis have previously been shown to result in impairments in olfactory perceptual learning. We thus hypothesized that augmentation of NA activity through enrichment or pharmacological manipulation may support improvement in olfactory discrimination ability through positive effects on olfactory neurogenesis. To test this, mice treated with saline, dexefaroxan, or labetalol and subjected or not to olfactory enrichment were injected beforehand with BrdU to track the survival of newly born cells. At the end of testing, mice were killed and the density of newly born cells was assayed in the OB.

We observed significant differences between experimental groups on the density of adult-born cells $\left(F_{(4,16)}=4.612, p=\right.$ $0.011)$. More specifically, we found an increase in the density of surviving adult-born cells after odor enrichment $(p=0.002)$ or dexefaroxan treatment $(p=0.004)$ compared with saline-nonenriched mice. This indicated to us that in both conditions in which discrimination was improved, bulbar neurogenesis was also enhanced. In contrast, the density of BrdU-positive cells in mice injected with labetalol during enrichment was not different from the saline-non-enriched mice ( $p=0.179$; Fig. $2 A, B)$. Finally, we found that the treatment with labetalol alone did not modulate the level of neurogenesis $(p=0.240$ compared with control non-enriched animals; Fig. $2 B$ ).

Using BrdU/NeuN double-labeling in the granule cell layer (Fig. 2C), we found that olfactory enrichment and/or drug treatments did not affect the level of neuronal differentiation of adultborn cells $(p>0.05)$.

\section{Enrichment but not NA stimulation leads to regionalized survival of newly born cells}

It has previously been shown that olfactory enrichment leads to selective survival of adult-born cells within the $\mathrm{OB}$, with the greatest increase in neurogenesis occurring in regions that are responsive to odorant stimulation (Moreno et al., 2009). To test whether the distribution of surviving adult-born cells in the granule cell layer in enriched and drug-treated animals is regionally localized, we used a previously established method for newborn cell mapping (Mandairon et al., 2006d; Sultan et al., 2011; see Materials and Methods). We found a nonhomogeneous distribution of BrdU-positive cells in the OB (Fig. 2D). More precisely, to understand the relationship between behavioral performances and the spatial distribution of BrdUpositive cell, we first analyzed the similarities between groups of animals showing an enhancement of discrimination abilities (enriched and dexefaroxan-treated groups) versus groups that did not show such improvement (non-enriched and the two labetaloltreated groups, with and without enrichment) (Fig. 2D). To do so, we delimited for each map the regions with a high density of BrdUpositive cells (corresponding to values superior to mean $+2 \mathrm{SD}$ of control map) and compared these regions between the different maps by calculating a percentage of overlap. We found that the maps of enriched and dexefaroxan-treated animals showed more similarities $(51.56 \%$ of overlap) compared with the other maps (non- 
A

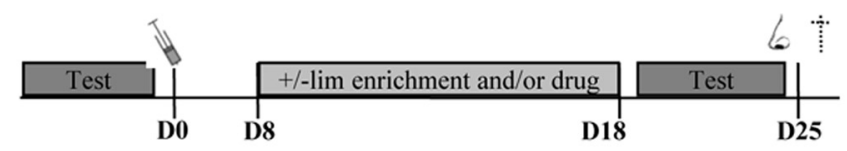

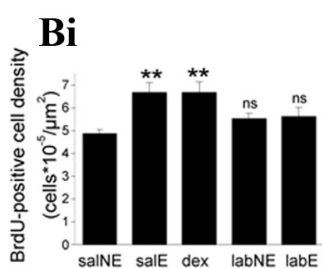

Bii

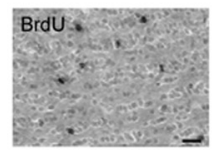

Cii

D
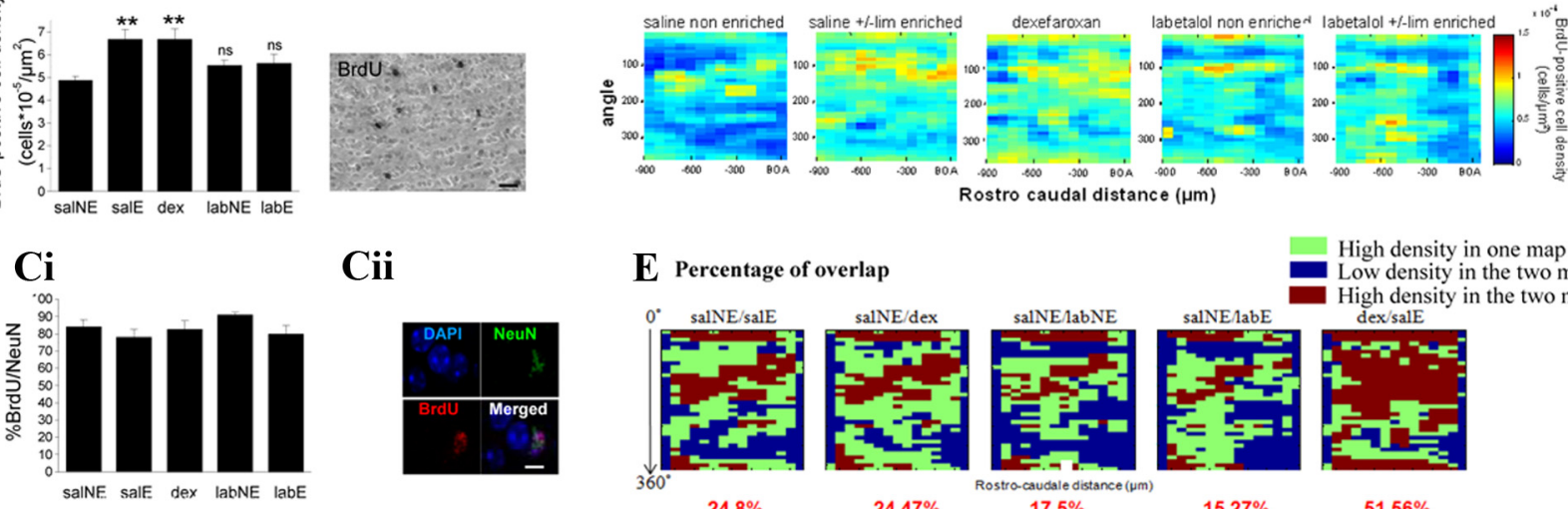

Rostro caudal distance $(\mu \mathrm{m})$

E Percentage of overlap

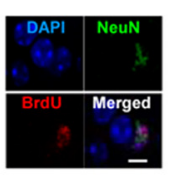

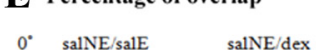

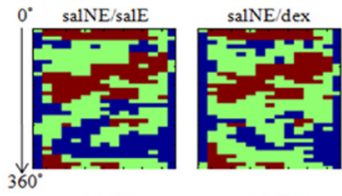

$24.8 \%$

Gi

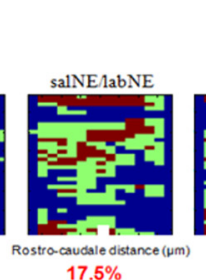

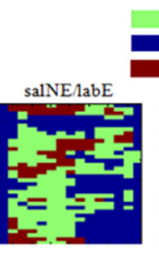

$15.27 \%$

High density in one map Low density in the two maps High density in the two maps (overlap) dex/sale

F
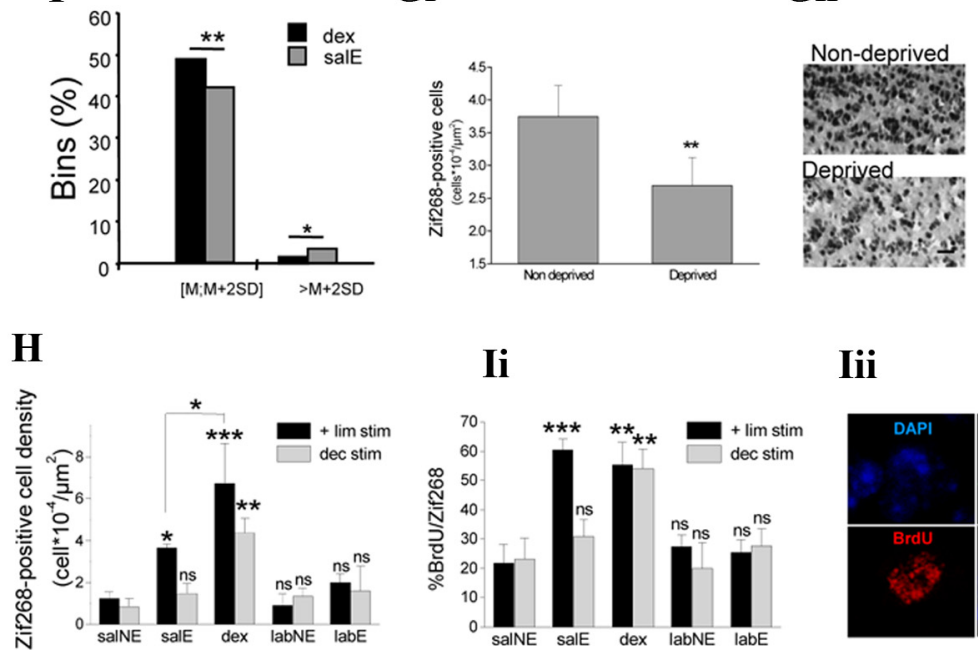

Ii

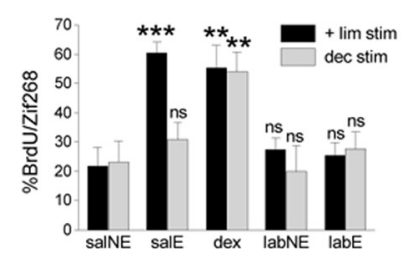

Iii

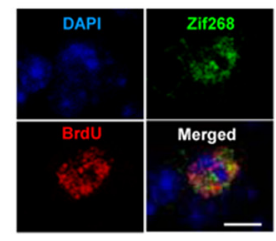

Figure 2. Newborn cell survival is modulated during perceptual learning and regulated by noradrenergic system. $A$, Experimental paradigm. BrdU was administered $8 \mathrm{~d}$ before the enrichment period and mice were killed $25 \mathrm{~d}$ after administration of BrdU. Animals were exposed to + limonene or decanal $1 \mathrm{~h}$ before they were killed. Bi, 0 dor enrichment and noradrenergic modulation affect neurogenesis. BrdU-positive cell density in the granule cell layer of the $\mathrm{OB}$ is increased in the saline-enriched and dexefaroxan-treated animals compared with the control non-enriched group. In both groups treated with labetalol with or without enrichment, the density of BrdU-positive cells is similar to that of the control group. Bii, Representative image of BrdU labeling. Scale bar, $15 \mu \mathrm{m}$. Ci, Quantification of BrdU/NeuN double-labeling in the granule cell layer showed no effect of the enrichment or drug treatment on the neuronal fate of adult-born cells. Cii, Pseudo-confocal imaging of BrdU/NeuN. Scale bar, $4 \mu \mathrm{m}$. D, Mapping of BrdU-positive cell density in the granule cell layer of the OB. Average maps of BrdU-positive cell density showed similarities between saline-enriched and dexefaroxan-treated animals compared with the other groups and correspond to animals whose discrimination abilities were improved. $\boldsymbol{E}$, Overlap maps were constructed by delimitation of regions with a high density of BrdU-positive cells, and these high-density areas were compared between maps and a percentage of overlap was calculated. $F$, Value of all bins of the enriched and dexefaroxan-treated maps was extracted and grouped in two categories: [mean; mean $+2 \mathrm{SD}$ ] representing intervals of mean values and [mean $+2 \mathrm{SD} ;+\infty$ ] representing intervals of more extreme values. The dexefaroxan-treated animals map presents more bins ranged in the interval of [mean; mean $+2 \mathrm{SD}$ ] and less bins in the interval of [mean $+2 \mathrm{SD} ;+\infty]$ compared with the enriched-animals map, indicating that adult-born cells are more widely distributed after noradrenergic treatment than after odor enrichment $\left(t\right.$ test for comparison of proportions; ${ }^{*} p<0.05 ;{ }^{* *} p<$ 0.005). The data are expressed as mean values \pm SEM. G, Gi, Olfactory deprivation decreased the density of Zif268-positive cells in the granule cell layer of the $0 B$ compared with the non-deprived side $\left({ }^{* *} p<0.005\right)$. Gii, Representative image of Zif268 labeling. Scale bar, $15 \mu \mathrm{m}$. $\boldsymbol{H}$, Enriched and dexefaroxan-treated animals displayed more granule cells expressing Zif268 in response to + limonene than did non-enriched animals or both groups of labetalol-treated animals (black bars). Only dexefaroxan-treated animals displayed an increase of Zif268-positive cells in response to decanal compared with the other groups (gray bars). li, In response to + limonene stimulation, enriched and dexefaroxan-treated animals displayed more adult-born neurons expressing Zif268 than did non-enriched animals or both groups of labetalol-treated animals. After decanal stimulation, only dexefaroxan-treated animals displayed more BrdU-positive cells expressing Zif268 compared with the other groups. lii, Confocal imaging of BrdU/Zif268. Scale bar, $4 \mu \mathrm{m} .{ }^{*} p<0.05 ;{ }^{* *} p<0.005 ;{ }^{* * *} p<0.001$. The data are expressed as mean values \pm SEM. salNE, Saline-non-enriched animals; salE, saline-enriched animals; dex, dexefaroxan-non-enriched animals; labNE, labetalol-non-enriched animals; labE, labetalol-enriched animals.

enriched vs enriched, $24.8 \%$; non-enriched vs dexefaroxan, $24.47 \%$; non-enriched vs non-enriched labetalol-treated, $17.5 \%$; nonenriched vs enriched labetalol-treated, 15.27\%) (Fig. 2E). In other words, BrdU-positive cell maps of enriched and dexefaroxantreated animals shared more similar features than with the three other maps, an observation which was in accordance with the behavioral performances.
Nevertheless, although sharing $51.56 \%$ of similarities, a more detailed analysis showed that the dexefaroxan-treated animals map was different from the enriched animals map. We measured the level of contrast (comparison of the distribution of high- vs low-density areas) in those two maps. For that purpose, we extracted from dexefaroxan and enriched animals maps the value of all bins and grouped them in two categories: the first category including values 
comprised between the mean and the mean + 2SD ([mean; mean $+2 \mathrm{SD}])$ which represent intervals of mean values. The other category included values above mean $+2 \mathrm{SD}$ $([$ mean $+2 \mathrm{SD} ;+\infty])$ which represent intervals of more extreme values. We observed that the dexefaroxan-treated animals map presents more bins ranged in the interval of [mean; mean+2SD] compared with enriched-animals map $(p=0.0112)$ and less bins ranged in the interval of [mean +2 $\mathrm{SD} ;+\infty](p=0.0328)$ (Fig. $2 F)$. These data indicated that adult-born cells are more broadly distributed after dexefaroxan treatment than after odor enrichment that could explain that dexefaroxan-treated animals are able to discriminate more odor pairs than the enriched animals.

In summary, we found that more surviving newborn cells was associated with better discrimination after learning. Furthermore, we showed that increases in the survival of adult-born cells with a broader distribution led to broad and nonspecific improvements in discrimination ability.

The noradrenergic system regulates the level of granule cell responsiveness to the learned-odorants

To determine whether the involvement of granule cell population in processing of the learned odors was related to the discrimination ability, we measured the expression of Zif268 as an index of cellular activation in animals from all five groups after odor stimulation. We first confirmed that the expression of Zif268 was modulated by the sensory activity, since sensory deprivation decreased its expression (Fig. 2G). We then assessed the responsiveness of granule cells, in response to +limonene (the odorant used for the enrichment regarding the groups of $+/$-limonene-enriched animals) or to an odorant that the animal had not previously been enriched with, decanal. We found that enriched and dexefaroxan-treated mice displayed increased granule cell Zif268 expression in response to +limonene (the learned odorant regarding the enriched animals) compared with all three other groups (group effect $F_{(4,12)}=8.728 p=0.002$; Fig. $2 \mathrm{H})$. Indeed, levels of Zif268 expression were significantly higher in enriched animals $(p=0.035)$ or dexefaroxan-treated animals $(p<0.0001)$ compared with salinenon-enriched animals. In addition, Zif268 expression was similar between saline-non-enriched animals and both non-enriched $(p=0.078)$ and enriched $(p=0.495)$ labetaloltreated animals (Fig. $2 \mathrm{H}$ ). When we assessed the responsiveness of granule cells in response to an odorant that the animal had not previously been enriched with, decanal, dexefaroxan-treated animals displayed an increase of Zif268-positive cells compared with the four other groups (group effect $F_{(4,14)}=4.889 p=0.011$; with saline-
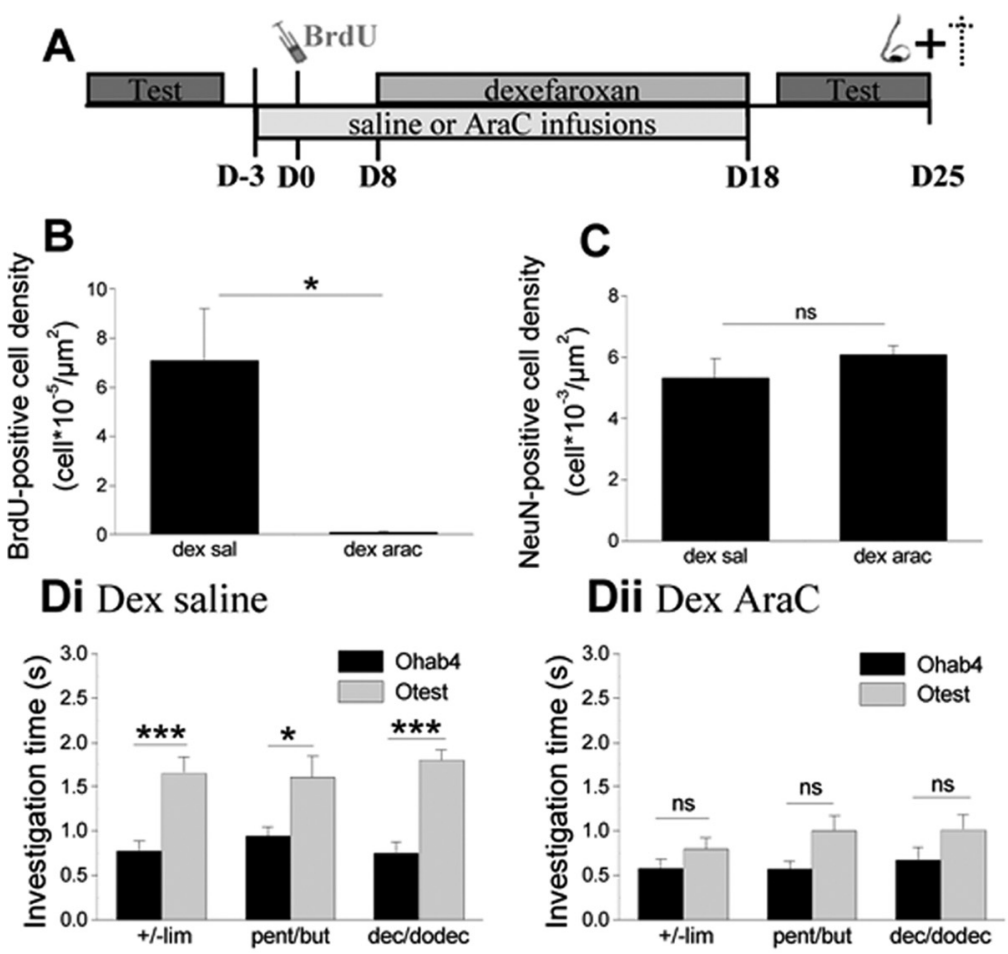

\section{Ei Dex saline}

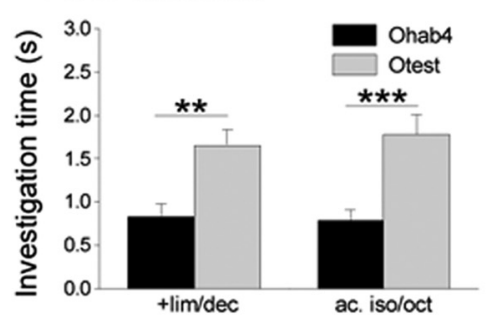

Eii Dex AraC
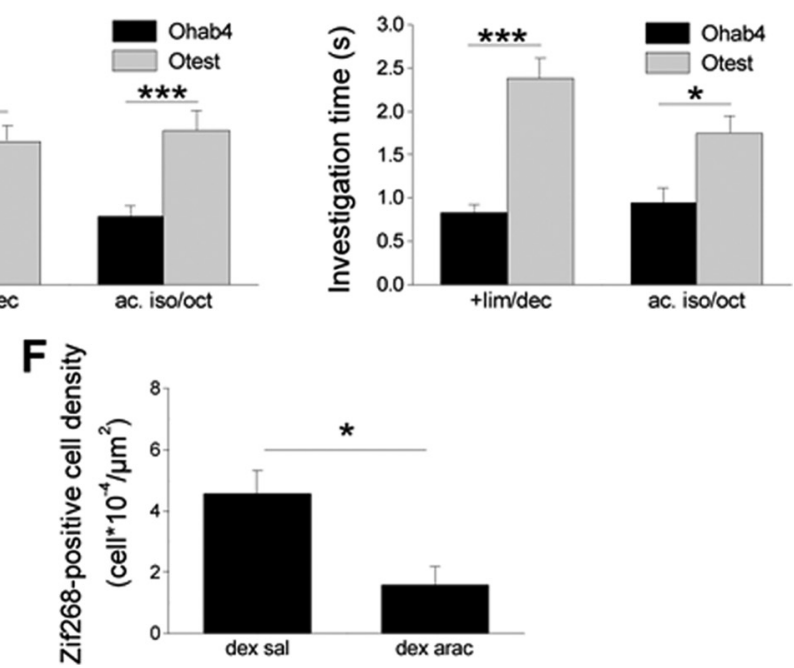

Figure 3. Olfactory perceptual learning requires the action of the noradrenergic system on adult-born neurons. $A$, Experimental design. Saline or AraC was locally infused $3 \mathrm{~d}$ before the administration of BrdU and lasting for $21 \mathrm{~d}$. Animals of both groups were treated with dexefaroxan once a day during $10 \mathrm{~d}$. B, Mice that received AraC had a significant reduction of BrdU-positive cell density in the granule cell layer of the $O B$ compared with the saline-infused animals. $C$, NeuN-positive cell density was similar between saline- and AraC-infused animals. Di, In the saline-infused animals, treatment with dexefaroxan improved discrimination for the three odor pairs tested. Dii, The strong reduction of bulbar neurogenesis in the AraC-infused group blocked the dexefaroxan treatment-induced improvement of discrimination. $\boldsymbol{E}$, Both groups of saline (Ei)- and $\mathrm{AraC}$ (Eii)-infused animals discriminate well a dissimilar pair of odorants (+ limonene vs decanal and isoamyl acetate vs octanal). $\boldsymbol{F}$, Zif268-positive cell density is superior in the saline-infused dexefaroxan-treated animals compared with the AraC infused. ${ }^{*} p<0.05 ;{ }^{* *} p<0.005$, ${ }^{* * *} p<0.001$. The data are expressed as mean values \pm SEM.

non-enriched similar to enriched ( $p=0.436)$, to labetalol-nonenriched $(p=0.542)$ labetalol enriched $(p=0.395)$ but significantly different from dexefaroxan ( $p=0.001$; Fig. 2Ii,Iii), which is in accordance with the fact that only dexefaroxan-treated animals are able to discriminate the decanal/dodecanone pair. These data showed that improvement of discrimination after stimulation of noradrenergic transmission is accompanied by an increase of 
granule cell responsiveness as in perceptual learning but with broader odor specificity.

Since it is known that after perceptual learning the functional activation of adult-born neurons is increased, we further examined whether this was also the case after modulation of the noradrenergic system. We assessed the percentage of adult-born granule cells expressing Zif268 in response to +limonene or decanal (Fig. 2I). Enriched and dexefaroxan-treated animals displayed more adult-born neurons expressing Zif268 in response to +limonene than non-enriched animals or both groups of labetalol-treated animals $\left(F_{(4,14)}=12.509, p<0.0001\right.$; with saline non-enriched vs enriched $p<0.0001$, vs dexefaroxan $p=$ 0.001 , vs labetalol non-enriched $p>0.05$, vs labetalol enriched $p>0.05$; Fig. 2I). After decanal stimulation, only dexefaroxantreated animals displayed more BrdU-positive cells expressing Zif268 compared with the other groups $\left(F_{(4,13)}=3.614 p=\right.$ 0.034 ; with saline non-enriched versus dexefaroxan $p=0.007$; Fig. 2I).

In summary, we found that stimulating the noradrenergic system improved discrimination, newborn cell survival and functional responsiveness of newborn cells similarly to what it was observed in perceptual learning. Conversely, blocking noradrenergic system during perceptual learning cancelled the effect of enrichment on discrimination, survival and functional involvement of newborn cells.

\section{Blocking neurogenesis prevents NA-induced improvement in olfactory discrimination ability}

We have shown here that the noradrenergic system plays a significant role in regulating olfactory learning and neurogenesis. We have demonstrated that the presence and distribution of adultborn cells are correlated with improvements in discrimination. To test whether enhanced adult-born cell survival resulting from increased NA activity is necessary for behavioral improvements in discrimination ability, we injected mice with dexefaroxan once daily for $10 \mathrm{~d}$, and in parallel, infused either the mitotic blocker AraC or saline into the subventricular zone of those same mice. This type of AraC treatment has previously been shown to block the division of constitutively proliferating cells (Enwere et al., 2004) in the subventricular zone and as a consequence inhibit neurogenesis (Moreno et al., 2009; Sultan et al., 2010) without affecting preexisting cells of the OB (Breton-Provencher et al., 2009). The AraC or saline infusion started $10 \mathrm{~d}$ before and was maintained during the $10 \mathrm{~d}$ period of noradrenergic stimulation (Fig. 3A).

We first confirmed that the AraC treatment induced a strong reduction in the density of BrdU-positive cells in the OB compared with saline-infused control mice $\left(F_{(1,5)}=15.943 p=0.01\right)$ (Fig. $3 B$ ). We previously showed that treatment with $\mathrm{AraC}$ in the exact same conditions did not induce a significant decrease of hippocampal neurogenesis (Moreno et al., 2009). Moreover, this treatment did not alter the structure of the $\mathrm{OB}$ since no significant modification of NeuN-positive cell density was observed in the granule cell layer of the AraC-infused group compared with the saline-infused group $\left(F_{(1,6)}=1.501 p>0.05\right.$; Fig. 3C).

Chronic infusion of AraC in the subventricular zone of dexefaroxan-treated animals had no effect on habituation memory, as evidenced by similar habituation curves obtained in treated and saline-infused animals (group effect $F_{(1,332)}=0.089$ $p=0.766$; see Table 4 for detailed statistics). Interestingly, in mice infused with AraC, dexefaroxan did not improve the ability of mice to discriminate any of the three odor pairs tested (Fig. 3 Dii; Table 4) in contrast to saline-infused animals (Fig. 3Di;
Table 4. Habituation and Discrimination performances after enrichment and/or drugs injections

\begin{tabular}{lllllll}
\hline & & \multicolumn{2}{l}{ ANOVA } & & \multicolumn{2}{l}{ Post hoc Fisher test } \\
\cline { 3 - 4 } Groups & Odor pairs & Fvalue & $p$ value & & Habituation & Discrimination \\
\hline Saline infusion + & $+/-\lim$ & $F_{(4,63)}=9.365$ & $p<0.0001$ & $p<0.0001$ & $p<0.0001$, yes \\
dexefaroxan & Pent/but & $F_{(4,57)}=3.231$ & $p=0.019$ & $p=0.002$ & $p=0.013$, yes \\
& Dec/dodec & $F_{(4,67)}=14.362$ & $p<0.0001$ & $p<0.0001$ & $p<0.0001$, yes \\
& $+\lim /$ dec & $F_{(4,40)}=6.949$ & $p<0.0001$ & $p<0.0001$ & $p=0.002$, yes \\
AraCinfusion + & iso/oct & $F_{(4,44)}=7.384$ & $p<0.0001$ & $p<0.0001$ & $p=0.000$, yes \\
dexefaroxan & $+/-\lim$ & $F_{(4,69)}=17.782$ & $p<0.0001$ & $p<0.0001$ & $p=0.383$, no \\
& Pent/but & $F_{(4,80)}=13.530$ & $p<0.0001$ & $p<0.0001$ & $p=0.105$, no \\
& Dec/dodec & $F_{(4,76)}=10.648$ & $p<0.0001$ & $p<0.0001$ & $p=0.213$, no \\
& $+\lim /$ dec & $F_{(4,57)}=8.580$ & $p<0.0001$ & $p<0.0001$ & $p<0.0001$, yes \\
& iso/oct & $F_{(4,50)}=9.222$ & $p<0.0001$ & $p<0.0001$ & $p=0.030$, yes \\
\hline
\end{tabular}

Pent, Pentanol; but, butanol; Dec, decanal; dodec, (2)-dodecanone; lim, limonene; iso, isoamyl acetate; oct, octanal.

Table 4). As a control, and to insure that treatment did not simply disrupt olfactory function, we found that discrimination between dissimilar odorants was normal and well performed by both groups of mice (Fig. 3Ei,Eii). Thus, we found that the presence of adult-born cells is required for improvements in discrimination ability induced by increased noradrenaline release.

Finally, treatment with dexefaroxan in saline-infused mice induced a significantly higher level Zif268 expression in the granule cell layer compared with the AraC-infused animals $\left(F_{(1,9)}=\right.$ $9.093 p=0.015$, Fig. $3 F$ ). This finding supports the implication of adult-born neurons in the increase in Zif268 expression observed in the granule cell layer after dexefaroxan treatment.

Since the effect of the noradrenergic system activation on the improvement of discrimination is abolished by neurogenesis blockade, it could be suggested that noradrenergic system controls perceptual learning through acting on newborn neurons within the OB.

To support these results we investigated whether noradrenergic fibers labeled with NET, projected directly onto newborn cells. To do so, we injected lentiviruses expressing GFP in the subventricular zone and $15 \mathrm{~d}$ later, analyzed both GFP and NET labeling in the OB. We found NET-positive fibers juxtaposed to newborn-GFP neurons (Fig. 4A).

Having established that newborn neurons receive noradrenergic innervations we investigate whether these cells are responsive to NA. In a recent publication Nai et al. (2010) reported that NA can either increases or decrease the excitability of adult granule cell depending on the applied concentration and the noradrenergic receptors subtype activated. Such effects were mediated by variation in the membrane resistance $\left(R_{\mathrm{m}}\right)$ through a modification of potassium conductance. To determine whether NA has similar effects on new born neurons, current-clamp recording were made from GFP-labeled cells in OB slices 12-18 d postinfection, i.e., the age at which new born neuron survival is affected by odor enrichment and the NA system. Newborn neurons did not spontaneously generate action potentials, presented an elevated membrane resistance $(3.3 \pm 0.4 \mathrm{G} \Omega)$, and fired few action potentials when depolarized by current injection (Fig. $4 B$ ), a characteristic of newborns granular cells (Carleton et al., 2003). Bath application of NA $(10 \mu \mathrm{M})$ significantly modified $R_{\mathrm{m}}$ in seven of eight newborn neurons recorded (leading to increased $R_{\mathrm{m}}$ in five neurons and decreased $R_{\mathrm{m}}$ in two neurons; Fig. $4 C, D$ ).

Together, these data show that 12- to 18-d-old newborn neurons are already sensitive to the noradrenergic neuromodulation. 
A

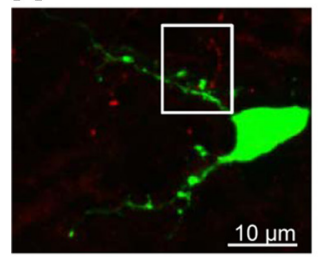

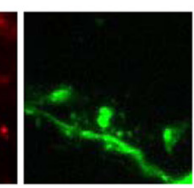

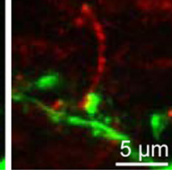

B

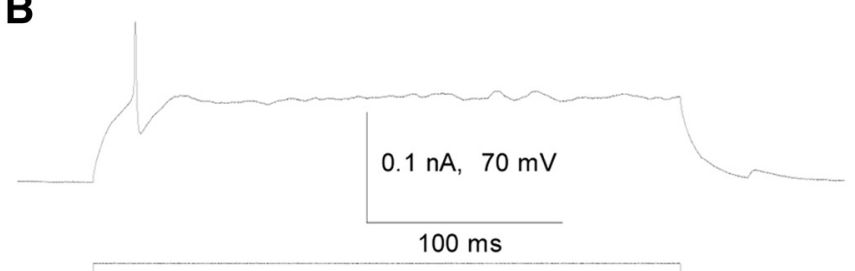

D

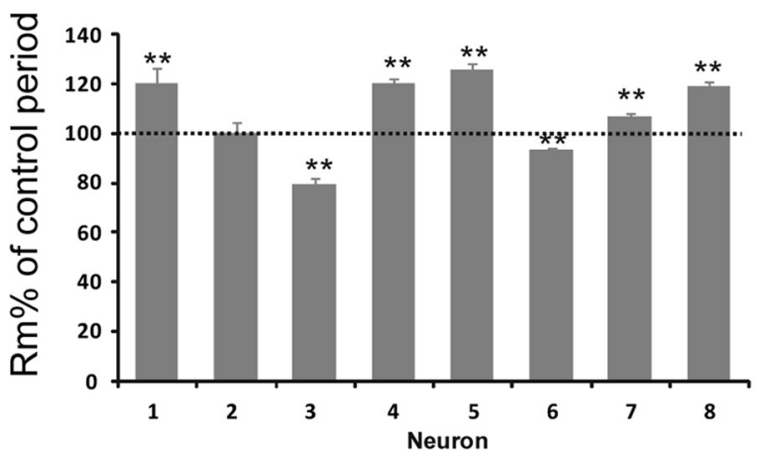

C

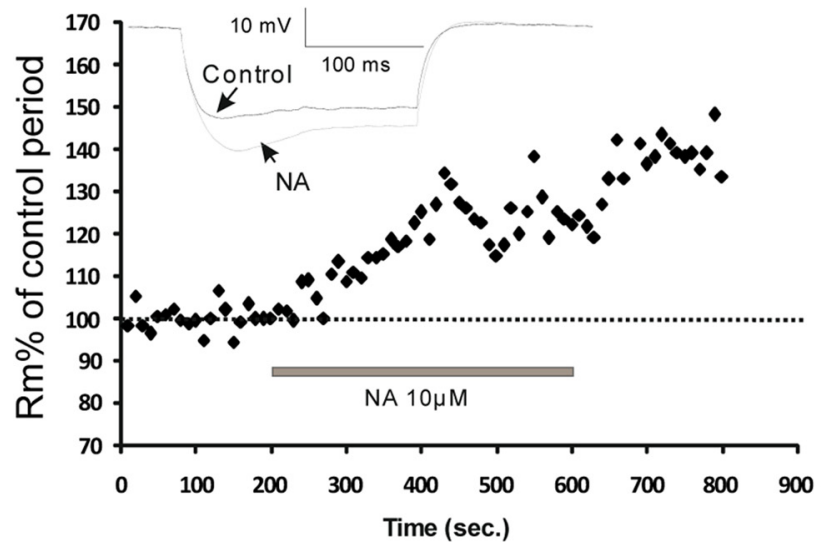

Figure 4. Adult-born neurons respond to noradrenaline. $A$, Representative of NET labeling in the bulbar granule cell layer of animals injected with GFP lentivirus. We found that NET-positive fibers project onto newborn neurons. $\boldsymbol{B}$, Depolarization induced by current injection produced only few action potential in adult-born neuron. $\boldsymbol{C}$, Time-plot of noradrenaline effect on the membrane resistance of a newborn neuron. Inset, Membrane hyperpolarization produced by injected current $(-0.005 \mathrm{nA})$ during control period (black trace) and in the presence of noradrenaline, $10 \mu \mathrm{m}$ (gray trace). $\boldsymbol{D}$, Modifications induced by noradrenaline on the membrane resistance of eight different adult-born neurons. ${ }^{* *} p<0.005$.

\section{Discussion}

Here, we show that noradrenaline is necessary for olfactory perceptual learning and that its efficacy requires the presence of adult-born neurons. Furthermore, we show for the first time that noradrenergic fibers impinge upon newly born cells and that newborn neurons are sensitive to application of noradrenaline. Based upon convergent lines of evidence we propose a model by which top-down release of noradrenaline supports the selective and region-specific incorporation of newly born neurons supporting enhanced discrimination abilities.

OB granule cells are continuously generated in adulthood (Lledo et al., 2006). The functional significance of adult-born neurons is a fundamental question in the field with broad implications. The survival of adult-granule cells has been shown to be modulated by associative learning (Alonso et al., 2006; Mandairon et al., 2006d; Sultan et al., 2010, 2011) required for remembering an operant olfactory learning (Mandairon et al., 2011) and necessary for perceptual learning (Moreno et al., 2009). However, the mechanisms underlying their integration into established neural networks are unknown. Here, we identify the noradrenergic system as a key signaling pathway regulating the selective survival of cells to support perceptual learning. Indeed, a $10 \mathrm{~d}$ treatment with $\alpha 2$-adrenoceptor antagonist dexefaroxan alone, which increased NA release in target areas (Mayer and Imbert, 2001), mimicked the effects of the odor enrichment by improving olfactory discrimination abilities. In contrast, a $10 \mathrm{~d}$ treatment by the mixed $\alpha 1$ - and $\beta$-adrenergic receptor antagonist labetalol blocked the effect of olfactory enrichment on discrimination. We further found that in groups in which olfactory discrimination is improved (10 d enrichment or dexefaroxan treatment) the density of Zif268-positive neurons in the granule cell layer is increased whereas labetalol blocked that enhancement in animals receiving enrichment. These data indicate that perceptual learn- ing requires activation of the noradrenergic system. These finding are further supported by the increase of $\mathrm{DBH}$ expression observed at the end of the perceptual learning which suggested an increased activity of the NA system during learning. These data are in accordance with previous studies showing activation of the noradrenergic system after enrichment (Veyrac et al., 2009; Rey et al., 2012) or leading to an increase in NA levels in the OB (Brennan et al., 1990; Veyrac et al., 2009).

NA modulation through $\alpha_{2}$-adrenoceptor antagonist dexefaroxan treatment alone increased the survival of adult-born cells, an effect that is accompanied by an improvement in discrimination ability. We then asked whether the presence of adult-born cells versus preexisting cells was necessary for the improvement in discrimination ability following NA stimulation. To do this, we assessed olfactory perceptual learning in animals in which neurogenesis was blocked by local infusion of AraC along with a parallel stimulation of the noradrenergic system by dexefaroxan treatment. The intracerebral infusion of AraC had no observed side effects (the animals were able to detect and discriminate odorants that were perceptually very different and thus easy to discriminate). In addition, AraC-infused animals had normal locomotor or exploratory activity, motivation, and performance in the acquisition of an associative olfactory task and spontaneous discrimination (Breton-Provencher et al., 2009; Moreno et al., 2009; Sultan et al., 2010). However, dexefaroxan-treated animals with ablation of neurogenesis demonstrated no perceptual learning, suggesting that the beneficial effect of increased noradrenergic tone requires the presence of adult-born cells. Importantly, even though NA drug injections lead to systemic modulation of NA, the loss of efficacy following local infusion of AraC in the subventricular zone, strongly suggests that the efficacy of NA to support perceptual learning is through selective effects on bulbar adult-born cells. Such a hypothesis is 
further bolstered by our confocal imaging and electrophysiological data showing that newborn cells are impinged upon by NA fibers and respond to NA.

Finally, in accordance with these findings, dexefaroxantreated AraC-infused animals showed no increase in the density of Zif268-positive cells, indicating that in the absence of adultborn cells, dexefaroxan-induced augmentation of granule cell activity did not occur. Thus we conclude that NA and adult-born cells are responsible for the increased granule cell activation accompanying perceptual learning.

The careful analysis of the spatial distribution of adult-born cells indicated a high level of similarity between the enriched and dexefaroxan-treated groups in agreement with the improvements in discrimination in those two groups. Nevertheless, the survival of adult-born cells in the dexefaroxan group is more widely distributed within the $\mathrm{OB}$ than in the saline-enriched group which is consistent with the fact that noradrenergic fibers terminate broadly across the bulb (McLean et al., 1989) and that dexefaroxan-treated group discriminate more odor pairs than the saline-enriched group. In animals enriched with the +limonene/-limonene pair, the more clustered distribution of adult-born cells suggests that experience could lead to selective activation of noradrenergic afferents in those regions activated by the odorants and support selective cell survival. However, such a hypothesis would require more testing. In contrast, the mixed $\alpha 1$ - and $\beta$-adrenergic receptor antagonist labetalol blocked the increase in neurogenesis in enriched mice. The injection of labetalol without any enrichment did not decrease the density of BrdU-positive cells compared with the control non-enriched animals, indicating that the NA blockade did not induce newborn cell death but rather prevented the increase of neurogenesis due to the enrichment in labetalol-enriched animals.

The role of NA in perceptual olfactory learning is reinforced by the fact that NA is important for the occurrence of long-term potentiation in the OB; indeed, NA antagonists disrupt induction of long-term potentiation (Wilson and Sullivan, 1994) and longterm potentiation in the $\mathrm{OB}$ seems to depend principally upon adult-born cells (Nissant et al., 2009). Here we found that, despite their immature electrical property, newborn cell are already sensitive to noradrenergic stimulation. NA is capable of triggering molecular mechanisms leading to long-term potentiation which could promote survival of newborn cells (Kermen et al., 2010) and increased excitability (Mouly et al., 1995). As a result, the neuromodulatory action of NA could alter receptive fields of the mitral cells to sharpen the contrast between odor neural representations and improve discrimination.

The present study examines the mechanisms underlying the survival of adult-born cells during perceptual learning. We found that the improvement of discrimination relied on the action of the noradrenergic system on the adult-born cells. Thus, our findings support a major role of the noradrenergic top-down control in perceptual learning, acting on inhibitory adult-born cells and refinement in odorant feature encoding, contributing to experiencedependent changes in odorant discrimination.

\section{References}

Alonso M, Viollet C, Gabellec MM, Meas-Yedid V, Olivo-Marin JC, Lledo PM (2006) Olfactory discrimination learning increases the survival of adult-born neurons in the olfactory bulb. J Neurosci 26:10508-10513.

Bauer S, Moyse E, Jourdan F, Colpaert F, Martel JC, Marien M (2003) Effects of the alpha 2-adrenoreceptor antagonist dexefaroxan on neurogenesis in the olfactory bulb of the adult rat in vivo: selective protection against neuronal death. Neuroscience 117:281-291.

Bovetti S, Gribaudo S, Puche AC, De Marchis S, Fasolo A (2011) From progenitors to integrated neurons: role of neurotransmitters in adult olfactory neurogenesis. J Chem Neuroanat 42:304-316.

Brennan P, Kaba H, Keverne EB (1990) Olfactory recognition: a simple memory system. Science 250:1223-1226.

Breton-Provencher V, Lemasson M, Peralta MR 3rd, Saghatelyan A (2009) Interneurons produced in adulthood are required for the normal functioning of the olfactory bulb network and for the execution of selected olfactory behaviors. J Neurosci 29:15245-15257.

Carleton A, Petreanu LT, Lansford R, Alvarez-Buylla A, Lledo PM (2003) Becoming a new neuron in the adult olfactory bulb. Nat Neurosci 6:507-518.

Cleland TA, Morse A, Yue EL, Linster C (2002) Behavioral models of odor similarity. Behav Neurosci 116:222-231.

Enwere E, Shingo T, Gregg C, Fujikawa H, Ohta S, Weiss S (2004) Aging results in reduced epidermal growth factor receptor signaling, diminished olfactory neurogenesis, and deficits in fine olfactory discrimination. J Neurosci 24:8354-8365.

Fletcher ML, Chen WR (2010) Neural correlates of olfactory learning: critical role of centrifugal neuromodulation. Learn Mem 17:561-570.

Gilbert CD, Sigman M, Crist RE (2001) The neural basis of perceptual learning. Neuron 31:681-697.

Gray CM, Freeman WJ, Skinner JE (1986) Chemical dependencies of learning in the rabbit olfactory bulb: acquisition of the transient spatial pattern change depends on norepinephrine. Behav Neurosci 100:585-596.

Imayoshi I, Sakamoto M, Ohtsuka T, Takao K, Miyakawa T, Yamaguchi M, Mori K, Ikeda T, Itohara S, Kageyama R (2008) Roles of continuous neurogenesis in the structural and functional integrity of the adult forebrain. Nat Neurosci 11:1153-1161.

Kermen F, Sultan S, Sacquet J, Mandairon N, Didier A (2010) Consolidation of an olfactory memory trace in the olfactory bulb is required for learning-induced survival of adult-born neurons and long-term memory. PLoS One 5:e12118.

Lazarini F, Mouthon MA, Gheusi G, de Chaumont F, Olivo-Marin JC, Lamarque S, Abrous DN, Boussin FD, Lledo PM (2009) Cellular and behavioral effects of cranial irradiation of the subventricular zone in adult mice. PLoS One 4:e7017.

Lledo PM, Alonso M, Grubb MS (2006) Adult neurogenesis and functional plasticity in neuronal circuits. Nat Rev Neurosci 7:179-193.

Lois C, Alvarez-Buylla A (1994) Long-distance neuronal migration in the adult mammalian brain. Science 264:1145-1148.

Mandairon N, Jourdan F, Didier A (2003) Deprivation of sensory inputs to the olfactory bulb up-regulates cell death and proliferation in the subventricular zone of adult mice. Neuroscience 119:507-516.

Mandairon N, Stack C, Kiselycznyk C, Linster C (2006a) Enrichment to odors improves olfactory discrimination in adult rats. Behav Neurosci 120:173-179.

Mandairon N, Sacquet J, Jourdan F, Didier A (2006b) Long-term fate and distribution of newborn cells in the adult mouse olfactory bulb: Influences of olfactory deprivation. Neuroscience 141:443-451.

Mandairon N, Stack C, Kiselycznyk C, Linster C (2006c) Broad activation of the olfactory bulb produces long-lasting changes in odor perception. Proc Natl Acad Sci U S A 103:13543-13548.

Mandairon N, Sacquet J, Garcia S, Ravel N, Jourdan F, Didier A (2006d) Neurogenic correlates of an olfactory discrimination task in the adult olfactory bulb. Eur J Neurosci 24:3578-3588.

Mandairon N, Peace S, Karnow A, Kim J, Ennis M, Linster C (2008a) Noradrenergic modulation in the olfactory bulb influences spontaneous and reward-motivated discrimination, but not the formation of habituation memory. Eur J Neurosci 27:1210-1219.

Mandairon N, Didier A, Linster C (2008b) Odor enrichment increases interneurons responsiveness in spatially defined regions of the olfactory bulb correlated with perception. Neurobiol Learn Mem 90:178-184.

Mandairon N, Sultan S, Nouvian M, Sacquet J, Didier A (2011) Involvement of newborn neurons in olfactory Associative learning? The operant or non-operant component of the task makes all the difference. J Neurosci 31:12455-12460.

Mayer P, Imbert T (2001) alpha2-Adrenoreceptor antagonists. IDrugs 4:662-676.

McLean JH, Shipley MT, Nickell WT, Aston-Jones G, Reyher CK (1989) Chemoanatomical organization of the noradrenergic input from locus coeruleus to the olfactory bulb of the adult rat. J Comp Neurol 285: $339-349$. 
Moreno MM, Linster C, Escanilla O, Sacquet J, Didier A, Mandairon N (2009) Olfactory perceptual learning requires adult neurogenesis. Proc Natl Acad Sci U S A 106:17980-17985.

Moriceau S, Sullivan RM (2004) Unique neural circuitry for neonatal olfactory learning. J Neurosci 24:1182-1189.

Mouly AM, Elaagouby A, Ravel N (1995) A study of the effects of noradrenaline in the rat olfactory bulb using evoked field potential response. Brain Res 681:47-57.

Nai Q, Dong HW, Linster C, Ennis M (2010) Activation of alphal and alpha2 noradrenergic receptors exert opposing effects on excitability of main olfactory bulb granule cells. Neuroscience 169:882-892.

Nissant A, Bardy C, Katagiri H, Murray K, Lledo PM (2009) Adult neurogenesis promotes synaptic plasticity in the olfactory bulb. Nat Neurosci 12:728-730.

Palouzier-Paulignan B, Duchamp-Viret P, Hardy AB, Duchamp A (2002) GABA(B) receptor-mediated inhibition of mitral/tufted cell activity in the rat olfactory bulb: a whole-cell patch-clamp study in vitro. Neuroscience 111:241-250.

Petreanu L, Alvarez-Buylla A (2002) Maturation and death of adult-born olfactory bulb granule neurons: role of olfaction. J Neurosci 22:6106-6113.

Rey NL, Sacquet J, Veyrac A, Jourdan F, Didier A (2012) Behavioral and cellular markers of olfactory aging and their response to enrichment. Neurobiol Aging 33:626.

Shea SD, Katz LC, Mooney R (2008) Noradrenergic induction of odorspecific neural habituation and olfactory memories. J Neurosci 28: 10711-10719.
Shipley MT, Halloran FJ, de la Torre J (1985) Surprisingly rich projection from locus coeruleus to the olfactory bulb in the rat. Brain Res 329:294-299.

Sullivan RM, Wilson DA (1994) The locus coeruleus, norepinephrine, and memory in newborns. Brain Res Bull 35:467-472.

Sullivan RM, Stackenwalt G, Nasr F, Lemon C, Wilson DA (2000) Association of an odor with activation of olfactory bulb noradrenergic beta-receptors or locus coeruleus stimulation is sufficient to produce learned approach responses to that odor in neonatal rats. Behav Neurosci 114:957-962.

Sultan S, Mandairon N, Kermen F, Garcia S, Sacquet J, Didier A (2010) Learning-dependent neurogenesis in the olfactory bulb determines longterm olfactory memory. FASEB J 24:2355-2363.

Sultan S, Lefort JM, Sacquet J, Mandairon N, Didier A (2011) Acquisition of an olfactory associative task triggers a regionalized down-regulation of adult born neuron cell death. Front Neurosci 5:52.

Veyrac A, Nguyen V, Marien M, Didier A, Jourdan F (2007) Noradrenergic control of odor recognition in a nonassociative olfactory learning task in the mouse. Learn Mem 14:847-854.

Veyrac A, Sacquet J, Nguyen V, Marien M, Jourdan F, Didier A (2009) Novelty determines the effects of olfactory enrichment on memory and neurogenesis through noradrenergic mechanisms. Neuropsychopharmacology 34:786-795

Wilson DA, Sullivan RM (1994) Neurobiology of associative learning in the neonate: early olfactory learning. Behav Neural Biol 61:1-18. 